\title{
Nailfold Capillaroscopy Findings in Diabetic Patients (A Pilot Cross-Sectional Study)
}

\author{
Alireza Rajaei ${ }^{*}$, Pooneh Dehghan², Zahra Farahani ${ }^{3}$ \\ ${ }^{1}$ Rheumatology, Loghman Hospital, Shahid Beheshti University of Medical Sciences, Tehran, Iran \\ ${ }^{2}$ Radiology, Taleghani Hospital, Shahid Beheshti University of Medical Sciences, Tehran, Iran \\ ${ }^{3}$ Maternal Fetal and Neonatal Research Center, Tehran University of Medical Sciences, Tehran, Iran \\ Email: arrajaei@gmail.com, poonehdehghan@yahoo.com, fetuspapyrus@gmail.com
}

Received 30 March 2015; accepted 23 April 2015; published 24 April 2015

Copyright (C) 2015 by authors and Scientific Research Publishing Inc.

This work is licensed under the Creative Commons Attribution International License (CC BY).

http://creativecommons.org/licenses/by/4.0/

(c) (i) Open Access

\begin{abstract}
Background: Microcirculation is affected in diabetes mellitus and Microvascular abnormalities cause persistent diabetic complications. The aim of this study was nailfold capillaroscopic assessment to describe the pathological changes (morphological and structural) in capillary of a large series of patients with type 1 and 2 diabetes. Methods: A cross-sectional study was carried out in a Nailfold Capillaroscopy Center (Tehran-Iran) between 2011 and 2014. The study included 235 types 1, 2 diabetic patients. All patients underwent 10 nailfolds capillaroscopy examinations. Microvascular architecture, disturbances capillary distribution, capillary morphology, capillary density, efferent/afferent limb ratio, sub-papillary venular plexus, and morphological abnormalities were evaluated. Conclusions were stated as normalor scleroderma pattern. Results of patients' capillaroscopic images were recorded and analyzed quantitatively and qualitatively. $P$ value < 0.05 was considered as statistical significance. Results: of all participants with mean age $59.91 \pm$ $12.39,183$ cases $(77.9 \%)$ were female and $52(22.1 \%)$ were male. Tortuosity of capillaries was more often observed in our subjects ( 235 cases) followed by angiogenesis (171 cases). Normal and early scleroderma patterns were observed in $195(83.0 \%)$ and 40 cases $(17.0 \%)$. Based on $P$ values, altered micro vascular architecture, capillary distribution and capillary morphology were more frequent in patients with scleroderma pattern in comparison to patients with normal pattern ( $P$ value $<\mathbf{0 . 0 5}$ ). Morphological abnormalities except from neo formation capillary and mega capillary were also significantly more common in patients with scleroderma pattern than patients in counterpart group $(P$ value $<0.05)$. Conclusion: Nailfold capillaroscopy as a non-invasive, diagnostic and prognostic method may potentially affect on diabetes outcome and control.
\end{abstract}

\section{Keywords}

Diabetes, Nail Fold Capillaroscopy, Normal Pattern, Scleroderma Pattern

\footnotetext{
${ }^{*}$ Corresponding author.
}

How to cite this paper: Rajaei, A., Dehghan, P. and Farahani, Z. (2015) Nailfold Capillaroscopy Findings in Diabetic Patients (A Pilot Cross-Sectional Study). Open Journal of Pathology, 5, 65-72. 


\section{Introduction}

Type 1, 2 diabetes is a worldwide disease with high risk of morbidity and early mortality. Persistent diabetic complications are mainly due to early stage in the pathogenesis of angiopathy and endothelial dysfunction. Both macro and microvasculature are affected in this disease by altered capillary flow, permeability associated with basement membrane thickening and blood cell velocity. Vascular damage, finally leads to eventual capillary obliteration. Morphological and functional changes in capillary microscopy have been reported in relation to vascular reactivity after induced ischemia [1]-[3].

Some techniques like nailfold capillaroscopy, laser Doppler flowmetry, retinal vessel analysis and 24-hour ambulatory blood pressure monitoring (24-hr ABPM) detect cardiovascular system damage once Type 1 or 2 diabetes is well established [2].

Nailfold capillaroscopy (NC) is a non-invasive, easy to perform, painless, and sensitive technique for evaluating microvascular involvement, mainly in Raynaud's phenomenon (RP), systemic sclerosis and connective tissue patients [3]-[5]. Moreover, capillaroscopy is now applied to predict the risk of development of future visceral complications and digital ulcers in patients with systemic disease [6]. The evaluation of the capillaroscopic pattern is not based on a single parameter, but on the judgment of an overall pattern resulting from the combination of numerical and morphologic characteristics such as capillary diameter (width), capillary length, shape, distribution, mean capillary density, presence of avascular areas, haemorrhages, neoangiogenic capillaries [5] [7]. The nailfold capillary bed is accessible and revealing capillaries lie parallel to skin allowing the whole capillary loops to be visualized [2].

Several capillary alterations have been explained in diabetes with poor metabolic control. In previous studies correlation between the severities of microvasculature changes and metabolic control of diabetes has also been reported [2]-[4]. Despite all these findings, little data exist on the relationship between microvascular changes in capillaroscopy and type 1, 2 diabetes features. Earlier diagnosis of vascular pathology with Capillaroscopy as a reliable method could be crucial for the therapy of diabetic patients [3]. Therefore the aim of this work was a quantitative and qualitative nailfold capillaroscopic assessment to describe the morphological and structural changes in capillary of a large series of type 1,2 diabetic subjects.

\section{Methods and Materials}

\subsection{Patients}

A cross-sectional, observational study of adolescent and adult with diabetes, aged 13 - 86 years old between October 2011 and October 2014 was carried out in Nailfold Capillaroscopy Center of Tehran Resalat Hospital, a private General Hospital in Tehran, Iran. The study included 240 patients suffering from diabetes based on their medical records and laboratory examinations for at least one year. Informed consent was obtained from each participant.

The inclusion criteria were patients with diabetes, without symptoms of diabetes decompensation or acute infection and with satisfactory clinical control. The exclusion criteria were any evidence of clinical cardiovascular and microvascular disease, vascular coexistent disorders, hypertension, hepatopathy, collagen vascular disease, skin diseases, smoking, infection, vascular effective drug use and missing data.

The study was approved by the Research and Ethics Committee of Tehran Resalat Hospital.

\subsection{Nailfold Capillaroscopy}

All patients underwent a nailfold capillaroscopy examination using a videocapillaroscope.

Videocap D1 (DS Medica, Sr1, Milano, Italy, 2011). The optical microscope was connected to a digital camera and computer.

Participants were studied in the morning between 9 - $12 \mathrm{am}$. We asked them to abstain from caffeine and smoking for 12 hours before the examination. The procedure was explained for patients. The patient was placed in a semi-supine position for 15 minutes in a comfortable ambient temperature of $22^{\circ} \mathrm{C}$ to $25^{\circ} \mathrm{C}$ with their hands at heart level.

As there may be a high variability in morphology in diabetic patients per nailfold, we evaluated every 10 nailfold in a patient. A drop of immersion oil was placed on the nail fold of finger to maximize the translucency.

For each image the following capillaroscopic parameters were assessed by an expert rheumatologist: Micro- 
vascular architecture, capillary distribution (morphology together the numbers), capillary density (the total number of erythrocyte-perfused capillaries per square millimeter of skin), efferent/afferent limb ratio, sub-papillary venular plexus (define according to Wertheimer's criteria, modified by Terreri et al.), and morphological abnormalities (bushy capillaries, Raynaud loops, megacapillaries) [4] [8] [9].

Conclusions were stated as normal, non-specific morphological abnormalities, and scleroderma pattern.

Although the combination of microvascular alterations in the nailfold and major morphological parameters including giant capillaries, A decreased number of loops ( $<30$ over $5 \mathrm{~mm}$ in the distal row of the nailfold), disorganization of the normal distribution of capillaries, budding (bushy) capillaries, the associated micro-haemorrhages when they start to collapse, the loss of capillaries with a decrease in their density ( 7 - 10 capillaries $/ \mathrm{mm}$ as the mean reference value), the neo-vascularisation, and reduced blood flow were detected as early capillaroscopic changes [10]-[12], we categorized our subjects in 2 groups according to Cutolo et al. [13]-[15]:

- Patients with two or more definitely abnormal morphological parameters (at least in two nailfolds) asscleroderma pattern group.

- Participants with homogeneous distribution of hairpin-shaped capillaries (comb-like structure), with a density of between 9 and 14 capillaries per mm or existence of just one abnormal parameter (non-specific morphological abnormalities) as normal capillaroscopic pattern.

Finally all gathered data were recorded and analyzed statistically.

\subsection{Statistical Analyses}

Capillaroscopic images from all patients were analyzed quantitatively and qualitatively using SPSS16.0. Data are presented as mean \pm standard deviation for continuous variables and $\mathrm{n} \%$ for categorical variables. Independent-samples $\mathrm{T}$ test and chi-square test was used to analyze the relationships between variables. With the proposed sample size of 240 , the study had a power of $90 \%$. P value $<0.05$ was used as statistical significance.

\section{Results}

Among 240 enrolled subjects, 5 cases were ineligible due to poor quality of capillaroscopy images, smoking, infection and missing data. Of all participants with mean age $59.91 \pm 12.39$, 183 cases ( $77.9 \%)$ were female and 52 (22.1\%) were male.

Normal and early scleroderma patterns were observed in 195 (83.0\%) and 40 cases (17.0\%), respectively.

Visibility of sub-papillary venular plexus in all cases was notable but micro vascular architecture in $27 \%$ of all patients was abnormal (Table 1). Moreover, tortuosity of capillaries was more often observed in our subjects (235 cases) followed by angiogenesis (171 cases). Morphological abnormalities in all subjects are reported in Figure 1.

Table 1. Capillaroscopic pattern in all participants.

\begin{tabular}{|c|c|c|}
\hline & & $\begin{array}{c}\text { Total }=235 \\
\text { N (\%) }\end{array}$ \\
\hline \multirow{2}{*}{ Micro vasculararchitecture } & Normal & 170 (71.9) \\
\hline & Altred & $65(27.7)$ \\
\hline \multirow{2}{*}{ Capillary distribution } & Regular & 230 (97.9) \\
\hline & Non homogenous & $5(2.1)$ \\
\hline \multirow{2}{*}{ Capillary morphology } & Homogenous & $231(98.3)$ \\
\hline & Non homogenous & $4(1.7)$ \\
\hline \multirow{2}{*}{ Capillary density } & Normal & 231 (98.3) \\
\hline & Reduced & $4(1.7)$ \\
\hline \multirow{2}{*}{ Sub-papillary venular plexus } & Visible & $235(100)$ \\
\hline & Non visible & 0 \\
\hline \multirow{2}{*}{ Efferent/Afferent limb ratio } & Normal & 233 (99.1) \\
\hline & Increased & $2(0.9)$ \\
\hline
\end{tabular}




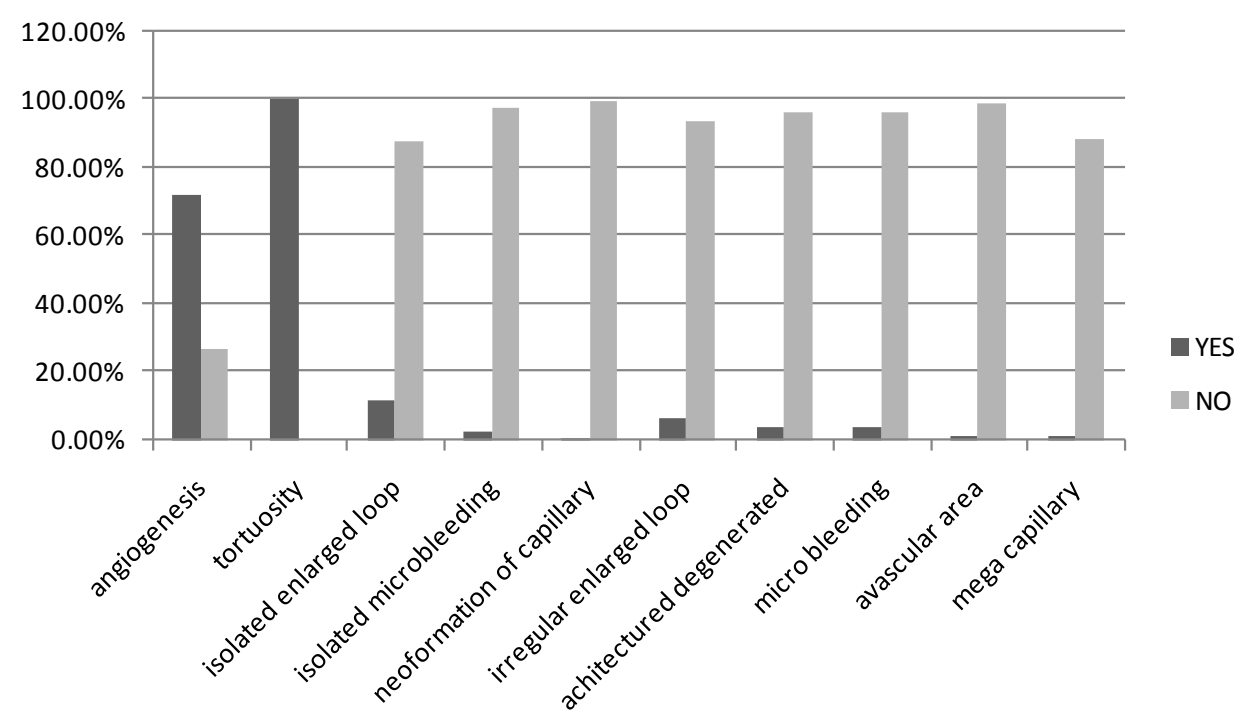

Figure 1. Morphological abnormalities in subjects.

Among 40 patients with scleroderma pattern, 33 of them were female. Tortuous capillaries, angiogenesis and altered micro vascular architecture were the most frequent morphological abnormalities in patients with scleroderma pattern. Based on P values, altered micro vascular architecture, capillary distribution and capillary morphology were more frequent in patients with scleroderma pattern in comparison to patients with normal pattern (P value $<0.05$ ). Morphological abnormalities except from neo formation capillary and mega capillary were also significantly more common in these patients (with scleroderma pattern) than patients in counterpart group (P value $<0.05$ ). Detailed data are demonstrated in Table 2 and Table 3.

However, mean age in subjects with scleroderma pattern was higher than normal pattern (61 \pm 8.81 vs. 59.69 \pm 13 years), this difference was not statistically significant ( $\mathrm{P}$ value $=0.543$ ). No correlation was also found between different patterns (normal or scleroderma) and participants' gender $(\mathrm{P}$ value $=0.439$ ).

Table 4 shows comparison of all micro vascular complications between men and women; statistical analysis showed no significant differences between both groups ( $\mathrm{P}$ value $>0.05$ ).

\section{Discussion}

We evaluated the frequency of nailfold capillaroscopic abnormalities of 235 patients with Type I and Type II diabetes mellitus and showed a high prevalence of pathological nailfold capillary changes.

According with our findings, morphological changes in diabetics' micro circulation were notable. This vascular heterogeneity may be related to significant autonomic neuropathy disturbances among population with this disease. Some other reports confirmed our results [2] [16].

In consistence to other investigations [3] [17], we saw a high frequency of capillary changes especially increased tortuosity of vascular loops and angiogenesis in diabetic patients. Kaminska-Winciorek et al. also showed an increased frequency of twisted capillaries in patients with diabetes type 1 and 2 [4]. Although we did not consider duration of disease, coiled capillaries were significantly reported in patients with diabetes with long-standing disease [18].

Of all participants $17 \%$ had different degrees of advanced microcirculation angiopathy (scleroderma pattern) that warned us for more attention against consequence complications.

In accordance with expectations, altered micro vascular architecture, capillary distribution and capillary morphology were seen more frequently in patients with scleroderma pattern in comparison to patients with normal pattern. We suppose that many factors like duration or severity of disease may be involved in micro circulation impairment. Barchettast et al. showed greater alterations of capillary length $(\mathrm{P}=0.004)$, distribution $(\mathrm{P}=0.02)$, and morphology $(\mathrm{P}=0.0001)$ in their subjects with diabetes [18].

In addition, we saw that Avascular areas and micro bleeding were significantly more frequent in participants with scleroderma pattern. In consistent to our results Hosking et al. indicated more common Avascular areas and 
Table 2. Comparison of capillaroscopic variables in patients with normal and scleroderma pattern.

\begin{tabular}{|c|c|c|c|c|}
\hline \multicolumn{2}{|c|}{ Variables } & $\begin{array}{c}\text { Normal Pattern } \\
\quad \mathbf{N}=195\end{array}$ & $\begin{array}{l}\text { Scleroderma Pattern } \\
\qquad \mathbf{N}=\mathbf{4 0}\end{array}$ & P Value \\
\hline Micro vascular architecture & $\begin{array}{l}\text { Normal } \\
\text { Altered }\end{array}$ & $\begin{array}{c}153(78.5) \\
41(21)\end{array}$ & $\begin{array}{l}16(40) \\
24(60)\end{array}$ & 0.000 \\
\hline Capillary distribution & $\begin{array}{c}\text { Regular } \\
\text { Non homogenous }\end{array}$ & $\begin{array}{c}195(100) \\
0(0)\end{array}$ & $\begin{array}{l}35(87.5) \\
5(12.5)\end{array}$ & 0.000 \\
\hline Capillary morphology & $\begin{array}{c}\text { Homogenous } \\
\text { Non homogenous }\end{array}$ & $\begin{array}{c}195(100) \\
0(0)\end{array}$ & $\begin{array}{c}36(90) \\
4(10)\end{array}$ & 0.001 \\
\hline Capillary density & $\begin{array}{l}\text { Normal } \\
\text { Reduced }\end{array}$ & $\begin{array}{c}193(99) \\
2(1)\end{array}$ & $\begin{array}{c}38(95) \\
2(5)\end{array}$ & 0.135 \\
\hline Efferent/Afferent limbRatio & $\begin{array}{c}\text { Normal } \\
\text { Increased }\end{array}$ & $\begin{array}{l}194(99.5) \\
1(0.5)\end{array}$ & $\begin{array}{c}39(97.5) \\
1(2.5)\end{array}$ & 0.312 \\
\hline Sex & $\begin{array}{c}\text { Male } \\
\text { Female }\end{array}$ & $\begin{array}{c}45(23.1) \\
150(76.9)\end{array}$ & $\begin{array}{c}7(17.5) \\
33(82.5)\end{array}$ & 0.534 \\
\hline
\end{tabular}

Table 3. Comparison of morphological abnormalities in patients with normal and scleroderma pattern.

\begin{tabular}{|c|c|c|c|c|}
\hline \multicolumn{2}{|c|}{ Morphological Abnormalities } & \multirow{2}{*}{$\begin{array}{c}\text { Normal Pattern } \\
\mathbf{N}(\%) \\
135(69.2) \\
60(30.8)\end{array}$} & \multirow{2}{*}{$\begin{array}{c}\text { Scleroderma Pattern } \\
\text { N (\%) } \\
36(90) \\
4(10)\end{array}$} & \multirow{2}{*}{$\begin{array}{r}\text { P Value } \\
0.006 \\
\end{array}$} \\
\hline Angiogenesis & $\begin{array}{l}\text { Yes } \\
\text { No }\end{array}$ & & & \\
\hline Tortuosity & $\begin{array}{l}\text { Yes } \\
\text { No }\end{array}$ & $\begin{array}{c}195(100) \\
0\end{array}$ & $\begin{array}{c}40(100) \\
0(0)\end{array}$ & 0.000 \\
\hline Isolated enlarged loop & $\begin{array}{l}\text { Yes } \\
\text { No }\end{array}$ & $\begin{array}{c}8(4.1) \\
187(95.9)\end{array}$ & $\begin{array}{l}10(47.5) \\
21(52.5)\end{array}$ & 0.000 \\
\hline Isolated microbleeding & $\begin{array}{l}\text { Yes } \\
\text { No }\end{array}$ & $\begin{array}{c}1(0.5) \\
194(99.5)\end{array}$ & $\begin{array}{c}4(10) \\
36(90)\end{array}$ & 0.003 \\
\hline Neo formation capillary & $\begin{array}{l}\text { Yes } \\
\text { No }\end{array}$ & $\begin{array}{c}1(0.5) \\
194(99.5)\end{array}$ & $\begin{array}{c}0(0) \\
40(100)\end{array}$ & .650 \\
\hline Irregular enlarged loop & $\begin{array}{l}\text { Yes } \\
\text { No }\end{array}$ & $\begin{array}{c}5(2.6) \\
190(97.4)\end{array}$ & $\begin{array}{c}9(22.5) \\
31(77.5)\end{array}$ & 0.000 \\
\hline Architecture derangement & $\begin{array}{l}\text { Yes } \\
\text { No }\end{array}$ & $\begin{array}{c}3(1.5) \\
192(98.5)\end{array}$ & $\begin{array}{c}4(10) \\
36(90)\end{array}$ & 0.017 \\
\hline Micro bleeding & $\begin{array}{l}\text { Yes } \\
\text { No }\end{array}$ & $\begin{array}{c}2(1) \\
193(99)\end{array}$ & $\begin{array}{c}5(12.5) \\
35(87.5)\end{array}$ & 0.002 \\
\hline Avascular area & $\begin{array}{l}\text { Yes } \\
\text { No }\end{array}$ & $\begin{array}{c}0(0) \\
195(100)\end{array}$ & $\begin{array}{c}2(5) \\
38(95)\end{array}$ & 0.028 \\
\hline Mega capillary & $\begin{array}{l}\text { Yes } \\
\text { No }\end{array}$ & $\begin{array}{c}1(0.5) \\
194(99.5)\end{array}$ & $\begin{array}{c}0(0) \\
40(100)\end{array}$ & 0.650 \\
\hline
\end{tabular}


Table 4. Comparison of micro vascular abnormalities between 2 genders.

\begin{tabular}{lccc}
\hline Variables & Women (\%) & Men (\%) & P Value \\
\hline Altered microvascular architecture & 29 & 25 & 0.612 \\
Non homogenous capillary distribution & 2.7 & 0 & 0.228 \\
Non homogenous capillary morphology & 2.2 & 0 & 0.282 \\
Reduced capillary density & 2.2 & 0 & 0.449 \\
Increased efferent afferent limb ratio & 1.1 & 0 & 0.439 \\
Angiogenesis & 71 & 78.8 & 0.264 \\
Toruosity & 100 & 100 & - \\
Isolated enlarged loop & 12 & 9.6 & 0.631 \\
Isolated microbleeding & 2.2 & 1.9 & 0.908 \\
Neo formation capillary & 0.5 & 0 & 0.593 \\
Irregular enlarged loop & 7.1 & 1.9 & 0.164 \\
Architecture derangement & 3.8 & 0 & 0.152 \\
Micro bleeding & 3.3 & 1.9 & 0.612 \\
Avascular area & 1.1 & 0 & 0.449 \\
Mega capillary & 0.5 & 0 & 0.593 \\
\hline
\end{tabular}

microhaemorrhages in participants with diabetes $(t=-2.33, \mathrm{P}=0.03)$. They demonstrated a positive association between recent HbA1c and the number of microhaemorrhages $(r=0.44, \mathrm{P}=0.03)$ [2].

We also found that isolated and irregular enlarged loops were seen more frequently in cases with scleroderma pattern. Halfoun et al. highlighted the role of abnormal capillaries adaptation to hypoxia in prolonged vasodilatation and irregular loops enlargement among diabetic patients [19]. Meyer et al. have also shown capillary diameters of the apical part and the venous limb were enlarged in the combined analysis of type 1, 2 diabetic patients [20].

A higher frequency of enlarged capillaries and nodular apical elongation were reported in type 2 diabetic patients with chronic clinical complications by Pazos-Moura et al. [21], as well.

Despite of sub-papillary venous plexus visibility can be influenced by local conditions including hyperkeratosis, skin pigmentation, injuries and edema [5], this parameter was visible in all our subjects.

Ingegnoli et al. reported that reduced capillary density may be detected very early in patients with scleroderma pattern [5]; however, this finding was not consistent with our results. Meyer et al. also demonstrated tortuosity and dilatations but normal density of nailfold capillaries of subjects with type 1 diabetes [20].

We could not find any correlations between microvascular abnormalities and participants' age and sex. Kaminska-Winciorek et al. and Barchetta et al. depicted that microcirculation alterations revealed by nailfold capillaroscopy was independent from age and sex in patients affected by diabetes [4] [16].

The main strength of our study was demonstration of capability of nailfold capillaroscopy; a useful method for revealing diabetic microangiopathy. Besides that, such a large sample size study had not been previously carried out in Iran and our results can provide comparable data source to other publications.

\section{Limitation}

We did not evaluate relationships between altered parameters and duration or severity of disease. Some participants' para clinical data like blood sugar status, HbA1c level, ... were not assessed, as well. Furthermore, in this project no control group was entered and studied. The answers to these questions definitely affect on our results interpretation.

\section{Conclusion}

Our results demonstrated that the presence of diabetes mellitus significantly influences on microcirculation mor- 
phology and structure, which may predispose to occurrence of sever late complications. Moreover, nailfold capillaroscopy as a non-invasive and diagnostic method may potentially affect on diabetes outcomes and diabetic control.

\section{Conflict of Interest}

The authors declare that there is no conflict of interests.

\section{Authors' Contributions}

Dr. Rajaie carried out the design and coordinated the study, participated in most of the experiments. Dr. Dehghan coordinated and carried out all the experiments and participated in manuscript preparation, Mrs. Farahani was responsible for Analysis of data and manuscript review. All authors have read and approved the content of the manuscript.

\section{References}

[1] Tibiriçá, E., Rodrigues, E., Cobas, R.A. and Gomes, M.B. (2007) Endothelial Function in Patients with Type 1 Diabetes Evaluated by Skin Pillary Recruitment. Microvascular Research, 73, 107-112. http://dx.doi.org/10.1016/j.mvr.2006.11.004

[2] Hosking, S.P., Bhatia, R., Crock, P.A., Wright, I., Squance, M.L. and Reeves, G. (2013) Non-Invasive Detection of Microvascular Changes in a Paediatric and Adolescent Population with Type 1 Diabetes: A Pilot Cross-Sectional Study. BMC Endocrine Disorders, 13, 41. http://dx.doi.org/10.1186/1472-6823-13-41

[3] Kuryliszyn-Moskal, A., Dubicki, A., Zarzycki, W., Zonnenberg, A. and Gorska, M., Microvascular Abnormalities in Capillaroscopy Correlate with Higher Serum IL-18 and sE-Selectin Levels in Patients with Type 1 Diabetes Complicated by Microangiopathy (2011) Folia histochemica et Cytobiologica/Polish Academy of Sciences. Polish Histochemical and Cytochemical Society, 49, 104-110.

[4] Kaminska-Winciorek, G., Deja, G., Polanska, J. and Jarosz-Chobot, P. (2012) Diabetic Microangiopathy in Capillaroscopic Examination of Juveniles with Diabetes Type 1. Postepy Higieny i Medycyny Doswiadczalnej (Online), 66, 51-59.

[5] Ingegnoli, F., Gualtierotti, R., Lubatti, C., Bertolazzi, C., Gutierrez, M., Boracchi, P., et al. (2013) Nailfold Capillary Patterns in Healthy Subjects: A Real Issue in Capillaroscopy. Microvascular Research, 90, 90-95. http://dx.doi.org/10.1016/j.mvr.2013.07.001

[6] Senet, P., Fichel, F., Baudot, N., Gaitz, J.P., Tribout, L. and Frances, C. (2014) Nail-Fold Capillaroscopy in Dermatology. Annales de Dermatologie et de Vénéréologie, 141, 429-437. http://dx.doi.org/10.1016/j.annder.2014.04.120

[7] Lambova, S.N., Hermann, W. and Muller-Ladner, U. (2012) Comparison of Qualitative and Quantitative Analysis of Capillaroscopic Findings in Patients with Rheumatic Diseases. Rheumatology International, 32, 729-735. http://dx.doi.org/10.1007/s00296-011-2222-2

[8] Terreri, M.T., Andrade, L.E., Puccinelli, M.L., Hilario, M.O. and Goldenberg, J. (1999) Nail Fold Capillaroscopy: Normal Findings in Children and Adolescents. Seminars in Arthritis and Rheumatism, 29, 36-42. http://dx.doi.org/10.1016/S0049-0172(99)80036-5

[9] Wertheimer, N. and Wertheimer, M. (1955) Capillary Structure: Its Relation to Psychiatric Diagnosis and Morphology. The Journal of Nervous and Mental Disease, 122, 14-27. http://dx.doi.org/10.1097/00005053-195507000-00002

[10] Cutolo, M., Sulli, A. and Vanessa, S. (2013) How to Perform and Interpret Capillaroscopy. Best Practice \& Research Clinical Rheumatology, 27, 237-248. http://dx.doi.org/10.1016/j.berh.2013.03.001

[11] Cutolo, M., Pizzorni, C., Elena Secchi, M. and Sulli, A. (2008) Capillaroscopy. Best Practice \& Research Clinical Rheumatology, 22, 1093-1108. http://dx.doi.org/10.1016/j.berh.2008.09.001

[12] Hoerth, C., Kundi, M., Katzenschlager, R. and Hirschl, M. (2012) Qualitative and Quantitative Assessment of Nailfold Capillaries by Capillaroscopy in Healthy Volunteers. Vasa, 41, 19-26. http://dx.doi.org/10.1024/0301-1526/a000159

[13] Cutolo, M., Pizzorni, C., Tuccio, M., Burroni, A., Craviotto, C., Basso, M., et al. (2004) Nailfold Videocapillaroscopic Patterns and Serum Autoantibodies in Systemic Sclerosis. Rheumatology (Oxford), 43, 719-726. http://dx.doi.org/10.1093/rheumatology/keh156

[14] Cutolo, M., Pizzorni, C., Secchi, M.E. and Sulli, A. (2008) Capillaroscopy. Best Practice \& Research Clinical Rheumatology, 22, 1093-1108. http://dx.doi.org/10.1016/j.berh.2008.09.001

[15] Cutolo, M. (2004) Atlas of Capillaroscopy. Walter Grassi, Patrizia Del Medico. 
[16] Barchetta, I., Riccieri, V., Vasile, M., Stefanantoni, K., Comberiati, P., Taverniti, L., et al. (2011) High Prevalence of Capillary Abnormalities in Patients with Diabetes and Association with Retinopathy. Diabetic Medicine, 28, 10391044. http://dx.doi.org/10.1111/j.1464-5491.2011.03325.X

[17] Kiesewetter, H., Jung, F., Körber, N., Wolf, S., Kieh, R., Frank, M., et al. (1986) Microcirculation and Hemorheology of Children with Type I Diabetes. Wiener Klinische Wochenschrift, 64, 962-968.

[18] Barchetta, I., Riccieri, V., Vasile, M., Stefanantoni, K., Comberiati, P., Taverniti, L. and Cavallo, M.G. (2011) High Prevalence of Capillary Abnormalities in Patients with Diabetes and Association with Retinopathy. Diabetic Medicine, 28, 1039-1044. http://dx.doi.org/10.1111/j.1464-5491.2011.03325.x

[19] Halfoun, V., Pires, M., Fernandes, T.J., Victer, K.K., Rodrigues, F. and Tavares R. (2003) Videocapillaroscopy and Diabetes Mellitus: Area of Transverse Segment in Nailfold Capillar Loops Reflects Vascular Reactivity. Diabetes Research and Clinical Practice, 61, 155-160.

[20] Meyer, M.F., Pfohl, M. and Schatz, H. (2001) Assessment of Diabetic Alterations of Microcirculation by Means of Capillaroscopy and Laser-Doppler Anemometry. Medizinische Klinik (Munich), 96, 71-77. http://dx.doi.org/10.1007/PL00002181

[21] Pazos-Moura, C.C., Moura, E.G., Bouskela, E., Torres-Filho, I.P. and Breitenbach, M.M. (1987) Nailfold Capillaroscopy in Diabetes Mellitus: Morphological Abnormalities and Relationship with Microangiopathy. Brazilian Journal of Medical and Biological Research, 20, 777-780. 